\title{
New insights into the biosynthesis of esterified oxylipins and their involvement in plant defense and developmental mechanisms
}

\author{
Manon Genva (i) - Firmin Obounou Akong • Mats X. Andersson • \\ Magali Deleu $\cdot$ Laurence Lins $\cdot$ Marie-Laure Fauconnier
}

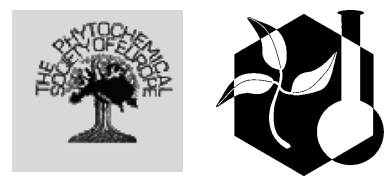

Received: 24 July 2018/Accepted: 21 October 2018/Published online: 27 October 2018

(C) The Author(s) 2018

\begin{abstract}
Plant oxylipins produced following oxidation of unsaturated fatty acids are structurally diverse metabolites that play crucial developmental and defensive roles. Whereas free oxylipins are well studied, oxylipins esterified in complex lipids such as galacto- and phospholipids are thought to be rare and have unclear roles. In the last few years, new analytical methods have been developed, leading to the discovery of many esterified oxylipins in a variety of plant species. This suggests that these molecules may be ubiquitous plant metabolites. While their precise functions are unclear, esterified oxylipins seem to play important roles in plant development and defense. This review focuses on new insights regarding diversity, biosynthesis and function of those interesting and understudied molecules.
\end{abstract}

M. Genva ( $₫)$ · F. Obounou Akong · M.-L. Fauconnier General and Organic Chemistry, University of Liège, Gembloux Agro-Bio Tech, Passage des déportés, 2, 5030 Gembloux, Belgium

e-mail: m.genva@uliege.be

M. Deleu · L. Lins

Laboratoire de Biophysique Moléculaire aux Interfaces, University of Liège, Gembloux Agro-Bio Tech,

Gembloux, Belgium

M. X. Andersson

Department of Biological and Environmental Sciences, University of Gothenburg, Göteborg, Sweden
Keywords Arabidopsides - Jasmonates · Lipoxygenase · Oxylipins · Plant defense

$\begin{array}{ll}\text { Abbreviations } \\ \text { (dn)OPDA } & \text { OPDA and dnOPDA } \\ \text { A. thaliana } & \text { Arabidopsis thaliana (L.) Heynh } \\ \text { ACX1 } & \text { Acyl-coenzyme A oxidase 1 } \\ \text { ADH } & \text { Alcohol dehydrogenase } \\ \text { AGAP1 } & \text { Acylated galactolipid associated } \\ & \text { phospholipase 1 } \\ \text { AOC } & \text { Allene oxide cyclase } \\ \text { AOS } & \text { Allene oxide synthase } \\ \text { DES } & \text { Divinyl ether synthase } \\ \text { 4,5-ddhJ } & \text { 4,5-Didehydro-jasmonic acid } \\ \text { DGDG } & \text { Digalactosyldiacylglycerol } \\ \text { DGMG } & \text { Digalactosylmonoacylglycerol } \\ \text { dnOPDA } & \text { 12-Dinor-oxo-phytodienoic acid } \\ \text { DOX } & \alpha \text {-Dioxygenase } \\ \text { DW } & \text { Dry weight } \\ \text { EAS } & \text { Epoxy alcohol synthase } \\ \text { EPB } & \text { Epibrassinolide } \\ \text { FW } & \text { Fresh weight } \\ \text { GC } & \text { Gas chromatography } \\ \text { HOD } & \text { Hydroxylinoleic acid } \\ \text { HOT } & \text { Hydroxylinolenic acid } \\ \text { HPHT } & \text { Hydroperoxyhexadecatrienoic acid } \\ \text { HPL } & \text { Hydroperoxyde lyase } \\ \text { HPLC } & \text { High-performance liquid } \\ & \text { chromatography } \\ \text { HPOD } & \text { Hydroperoxylinoleic acid } \\ & \end{array}$




$\begin{array}{ll}\text { HPOT } & \text { Hydroperoxylinolenic acid } \\ \text { HTA } & \text { Hexadecatrienoic acid } \\ \text { JA } & \text { Jasmonic acid } \\ \text { JA-Ile } & \text { JA-isoleucine } \\ \text { KAT } & \text { 3-Ketoacyl-coenzyme A oxidase } \\ \text { KOD } & \text { Ketolinoleic acid } \\ \text { KOT } & \text { Ketolinolenic acid } \\ \text { LA } & \alpha \text {-Linolenic acid } \\ \text { LEA } & \text { Linoleic acid } \\ \text { LOX } & \text { Lipoxygenase } \\ \text { MFP } & \text { Multifunctional protein } \\ \text { MGDG } & \text { Monogalactosyldiacylglycerol } \\ \text { MGMG } & \text { Monogalactosylmonoacylglycerol } \\ \text { MS } & \text { Mass spectrometry } \\ \text { MS/MS } & \text { Tandem mass spectrometry } \\ \text { OPC-4 } & \text { 4-(3-oxo-2-(Pent-2- } \\ & \text { enyl)cyclopentyl)butanoic acid } \\ \text { OPC-6 } & \text { 6-(3-oxo-2-(Pent-2- } \\ & \text { enyl)cyclopentyl)hexanoic acid } \\ \text { OPC-8 } & \text { 8-(3-oxo-2-(Pent-2- } \\ & \text { enyl)cyclopentyl)octanoic acid } \\ \text { OPDA } & \text { 12-oxo-Phytodienoic acid } \\ \text { OPDA-Ile } & \text { OPDA-isoleucine } \\ \text { OPR2 } & \text { OPDA reductase 2 } \\ \text { OPR3 } & \text { OPDA reductase 3 } \\ \text { PG } & \text { Phosphatidylglycerol } \\ \text { PI } & \text { Phosphatidylinositol } \\ \text { PLA } 1 & \text { Phospholipase A1 } \\ \text { PLIP2 } & \text { Plastid lipase 2 } \\ \text { PLIP3 } & \text { Plastid lipase 3 } \\ \text { POX } & \text { Peroxygenase } \\ \text { tnOPDA } & \text { Tetranor-OPDA } \\ & \end{array}$

\section{Introduction}

Oxylipins are crucial compounds in plants, playing important developmental roles and being involved in plant defense mechanisms. This family of molecules includes structurally diverse metabolites that are all produced following oxidation of unsaturated fatty acids, comprising hydroperoxides, keto acids, hydroxides, oxoacids, divinyl ethers and aldehydes (Blée 2002; Andreou et al. 2009; Mosblech et al. 2009). While free oxylipins have been studied for years and have well known functions, the roles of plant oxylipins esterified in complex lipids such as galacto- and phospholipids remain unclear (Vu et al. 2012; Griffiths 2015). In 2001, a first oxidized galactolipid was completely characterized in Arabidopsis thaliana (L.) Heynh (Stelmach et al. 2001). Since then, a wide range of esterified oxylipins have been described in the same species (Ibrahim et al. 2011; Vu et al. 2012, 2014). More recently, esterified oxylipins were described outside the Brassicaceae, raising the question as to the extent of their occurrence and their biological functions. Many studies have indicated that these molecules might play important roles in plant defense and developmental processes; however, their precise biological roles remain unclear. This review focuses on new insights concerning esterified oxylipin diversity, biosynthesis and function in plant defense mechanisms and developmental processes.

\section{Esterified oxylipins diversity}

Plant esterified oxylipins have been known to exist for many years, but have only been completely structurally characterized in the last two decades. As older analytical methods made full characterization of mixtures composed of oxidized complex lipids very complicated, only the oxylipin parts of the molecules were usually analyzed following methanolysis or otherwise liberating the free oxylipin fatty acid. Generally, the whole structure was not determined (Feussner et al. 1995; Hamberg and Hamberg 1996; Fauconnier et al. 2008). For example, in 1995, Feussner et al. demonstrated that esterified (13S)hydroxy-(9Z,11E)-octadecadienoic acid is formed during germination of cucumber cotyledons, suggesting a role for this lipoxygenation product in plant developmental processes (Feussner et al. 1995). Esterified (15R)-hydroxylinoleic acid was also found in seeds of Avena sativa L., cv. Freja and Vital (Hamberg and Hamberg 1996). In 2008, it was shown that potato cultivars produced different profiles of esterified oxylipins upon fungal infection, including colneleic and colnelenic acids, 9-hydroxylinolenic acid (9-HOT) and 13-HOT (Fauconnier et al. 2008). Miersch et al. (2004) showed that high quantities of diverse esterified oxylipins containing HOTs, hydroxylinoleic acids (HOD), ketolinolenic acids (KOT), ketolinoleic acids (KOD) and hydroperoxylinoleic 
acids (HPODs) are found in tomato flower organs (Miersch et al. 2004). Finally, treatment of tomatoes with avirulent rhizobactezrium Pseudomonas putida BTP1 induces accumulation of esterified 13-HPOD, 13-hydroperoxylinolenic acid (13-HPOT), 13-HOT and 13-HOD, which are then released as free compounds upon Botrytis cinerea infection (Mariutto et al. 2014). Interestingly, all those studies highlighted esterified oxylipin ubiquity in plant species and organs.

More recently, advanced analytical methods, such as high-performance liquid chromatography (HPLC)tandem mass spectrometry (MS/MS) (Stelmach et al. 2001; Böttcher and Weiler 2007; Glauser et al. 2008) and direct infusion MS/MS (Buseman et al. 2006; Vu et al. 2012), have made analyzing complex lipid mixtures less problematic (Göbel and Feussner 2009). Those methods facilitate the structural characterization of complex lipids; however, they cannot separate closely related positional isomers and fully determine their stereochemistry. Even so, many esterified oxylipins have been described, allowing a better understanding of their biosynthetic pathways and functions. While these molecules seem to be highly diverse, their precise biological roles still remain unclear.

\section{Oxidized glycolipids}

\section{Arabidopsides}

The first esterified oxylipin, sn1-O-(9S,13S-12-oxophytodienoyl)-sn2-O-(7Z,10Z,13Z-hexadecatrienoyl)sn3-O-( $\beta$-D-galactopyranosyl)-glycerol, was completely characterized in $A$. thaliana by Stelmach et al. (2001), using nuclear magnetic resonance and mass spectrometry. Thereafter, other galactolipids containing 12-oxo-phytodienoic acid (OPDA) and 12-dinor-oxo-phytodienoic acid (dnOPDA) were discovered in the same species and collectively named arabidopsides (from A to G; Fig. 1). Arabidopsides were defined as oxidized monogalactosyldiacylglycerols (MGDG) or digalactosyldiacylglycerols (DGDG) produced by A. thaliana, containing at least one OPDA or dnOPDA residue (Hisamatsu et al. 2003, 2005). Arabidopsides $A$ and $C$ are oxidized MGDGs and DGDGs, respectively, each containing one OPDA residue esterified in the $s n-1$ position and one dnOPDA residue esterified in the $s n-2$ position (Hisamatsu et al. 2003, 2005). Arabidopsides B and D are, in turn, oxidized MGDGs and DGDGs, containing OPDA residues esterified to the $s n-1$ and $s n-2$ positions, respectively (Hisamatsu et al. 2003, 2005). Arabidopside $\mathrm{F}$ is a monogalactosyldiacylglyceride containing esterified dnOPDA in the $s n-2$ position (Shigemori et al. 2006). Interestingly, two arabidopsides, $\mathrm{E}$ and $\mathrm{G}$, contain one additional OPDA esterified on the C6 position of the galactolipid moiety (Andersson et al. 2006; Kourtchenko et al. 2007).

Arabidopsides possess several asymmetric centers whose absolute configuration has not been determined for all known arabidopside molecular species. Glycerol asymmetric carbons in arabidopsides A (snl-O(12-oxophytodienoyl)-sn2-O-(dinor-oxophytodienoyl)sn3-O-( $\beta$-D-galactopyranosyl)-glycerol) and B (snl, $s n 2$-di-O-(12-oxophytodienoyl)- $s n 3-\mathrm{O}-(\beta$-D-galactopyranosyl)-glycerol) were determined by subsequent enzymatic hydrolysis and optical rotation comparison and reported to have a $S$ configuration (Hisamatsu et al. 2003). In arabidopside D (sn1,sn2-diO-(12-oxophytodienoyl)-sn3-O-(6-O-( $\alpha$-D-galactopyranosyl)- $\beta$-D-galactopyranosyl)-glycerol), the same asymmetric carbon was analyzed after derivatization using chiral gas chromatography (GC) and was reported as a racemic mixture of $R$ and $S$ forms (Hisamatsu et al. 2005). In other arabidopsides, the absolute configuration of the glycerol moiety has not been determined yet. Otherwise, esterified OPDA and dnOPDA ((dn)OPDA) were determined to be mainly present as $S, S$ stereoisomers. Chiral GC analysis of $(\mathrm{dn})$ OPDA in arabidopsides isolated from unstressed A. thaliana reported a 10:3 stereoisomer ratio of $S, S /$ $R, R$ (dn)OPDA (Hisamatsu et al. 2003, 2005). It was also shown by subsequent methyl-esterification and chiral HPLC analysis that (dn)OPDAs formed after freeze-thawing in A. thaliana are only present as $S, S$ stereoisomers (Nilsson et al. 2016).

More recently, a diverse range of similar molecules was identified in A. thaliana by direct infusion MS (Ibrahim et al. 2011; Vu et al. 2012, 2014). This, with information detailed below, shows there was much more diversity in those oxidized galactolipids than had been found previously. Furthermore, previously characterized arabidopsides A-D, as well as four novel oxidized galactolipids, were identified in wounded $A$. thaliana leaves (Glauser et al. 2008). Those metabolites were described as monogalactosylmonoacylglycerols (MGMG) and digalactosylmonoacylglycerols (DGMG) containing (dn)OPDA esterified in the $s n-1$ 
or in the $s n-2$ position, namely sn2-O-(dinor-oxophytodienoyl)-monogalactosyl monoglyceride, sn1-O(12-oxophytodienoyl)-monogalactosyl monoglyceride, sn2-O-(dinor-oxophytodienoyl)-digalactosyl monoglyceride and sn1-O-(12-oxophytodienoyl)-digalactosyl monoglyceride (Glauser et al. 2008).

While arabidopsides were firstly discovered in $A$. thaliana leaves, those molecules have also been found in flowers and stems of unstressed plants (Zhao et al. 2013); however, they were not detected in roots, even after wounding (Grebner et al. 2013), or in seeds (Wang et al. 2017). Whereas arabidopsides are constitutively produced in low quantities by $A$. thaliana, their levels peak under different biotic and abiotic stress conditions, such as mechanical wounding (Buseman et al. 2006; Kourtchenko et al. 2007), exposure to Pseudomonas syringae avirulence proteins AvrRpm1 and AvrRpt2 (Andersson et al. 2006; Kourtchenko et al. 2007), P. syringae infection (Vu et al. 2012) and low temperature treatment ( $\mathrm{Vu}$ et al. 2012). For example, production of arabidopsides A, B and D increases up to 1000 -fold within $15 \mathrm{~min}$ of mechanical wounding, with concentrations of more than 2,5 nmol/mg DW for arabidopside A (Buseman et al. 2006). Upon wounding, arabidopsides not only accumulate in A. thaliana stressed leaves but, to a minor extent, also in distal unwounded leaves of the same plant (Glauser et al. 2009). Moreover, in $A$. thaliana the esterified oxylipin profile depends on the nature of the stress; for example, wounding induces much more oxidized MGDG production than low temperature treatment ( $\mathrm{Vu}$ et al. 2012).

Interestingly, cell disruption in A. thaliana leaves by freeze-thawing leads to the formation of arabidopsides A, B, C, D, E and G (Nilsson et al. 2012), whereas it is known not to generate free jasmonic acid (JA) (Glauser et al. 2009). Among oxidized MGDG species, arabidopsides A and $\mathrm{B}$ are produced first and peak approximatively $5 \mathrm{~min}$ after freeze-thawing. Those molecules slowly decrease thereafter, while arabidopside $\mathrm{E}$ and $\mathrm{G}$ production increases and peaks approximately $30 \mathrm{~min}$ after freezethawing (Nilsson et al. 2012, 2016).

With regard to other species, arabidopsides A and B have been detected upon wounding of Arabidopsis arenosa (L.) Lawalrée (Böttcher and Weiler 2007). The same year, these molecules were also reported in two other Arabidopsis species and three other species of the Brassicaceae (Böttcher 2007), confirming that they are not limited to the genus Arabidopsis. This conclusion was
Fig. 1 Structure of arabidopsides, linolipins and phosphatidylinositol containing colneleic acid. Arabidopsides are oxidized MGDGs and DGDGs containing OPDA and/or dnOPDA. Linolipins are oxidized MGDGs and DGDGs containing at least one ( $\omega 5 Z)$-etherolenic acid chain. 16:0/colneleic acidphosphatidylinositol is an oxidized phosphatidylinositol containing one colneleic acid residue. Determined asymmetric carbons absolute configurations are represented on the figure

supported by the discovery in 2015 of OPDA-containing lipids in unstressed fresh leaves and freeze-thawed leaves of three other Arabidopsis species and one other species from the Brassicaceae (Nilsson et al. 2015). In 2017, OPDA and arabidopsides A, C and D were reported to be induced in another Brassicaceae plant, Erucastrum canariense Webb \& Berthel, upon copper chloride spraying, and by mechanical wounding (Pedras and To 2017). As arabidopsides A and D isolated from $E$. canariense possessed different optical rotations to those that had been first isolated (Hisamatsu et al. 2003, 2005), it was suggested that they were stereoisomers of $A$. thaliana arabidopsides (Pedras and To 2017). Arabidopsides $\mathrm{A}$ and $\mathrm{D}$ were also detected in unstressed leaves of the Brassicaceae plant, Nasturtium officinale R. Br., and in leaves sprayed with copper chloride (Pedras and To 2017).

Whereas (dn)OPDA containing galactolipids where firstly described in Brassicaceae plants, a study found an OPDA-containing MGMG in Ipomoea tricolor Cav. (Convolvulaceae) (Ohashi et al. 2005). In the same way, arabidopsides were also detected in Melissa officinalis $\mathrm{L}$. (Lamiaceae) (Zábranská et al. 2012). Thereafter, it was demonstrated that Cirsium arverse (L.) Scop. (Asteraceae) also produces oxidized glycolipids upon infection by Chaetomium cochlioides, an endophytic fungi, since arabidopsides and other esters of MGDG and DGDG containing OPDA, dihydroOPDA and dihydroJA were detected (Hartley et al. 2015). While arabidopsides could not be detected in several tested plant species (Nilsson et al. 2015), the discovery in other non-Brassicaceae plants indicates they are more ubiquitous than thought upon first discovery (Table 1).

\section{Linolipins}

In 2009, the discovery of a second family of oxidized galactolipids was reported in leaves of Linum usitatissimum L., cv. Novotorzhski (Fig. 1). Those molecules were named linolipins A and B (Chechetkin et al. 2009). At the present time, four linolipins have been characterized. Linolipins are MGDGs and DGDGs, 


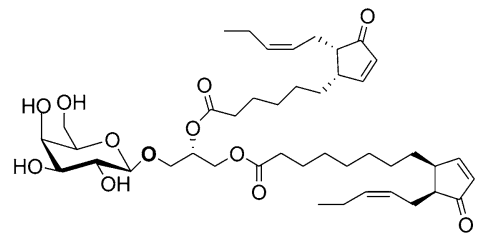

Arabidopside A
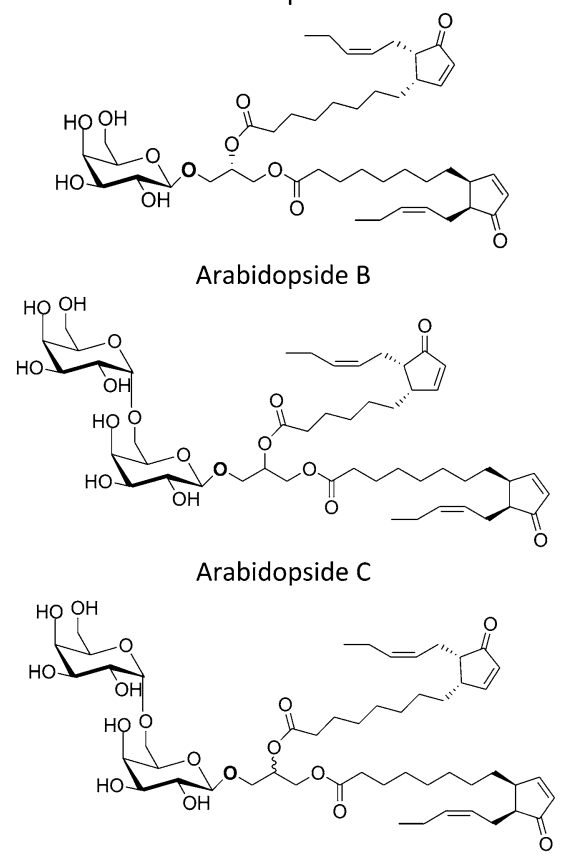

Arabidopside D

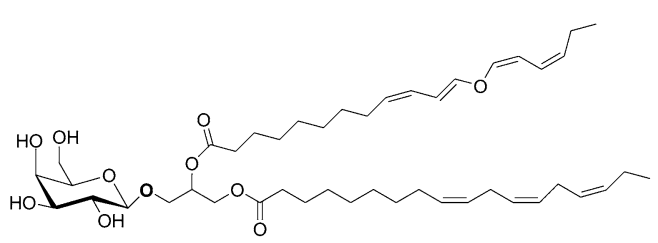

Linolipin A

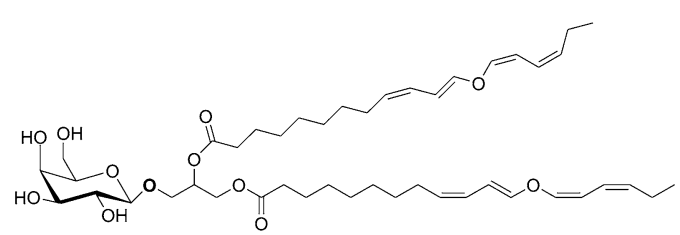

Linolipin B

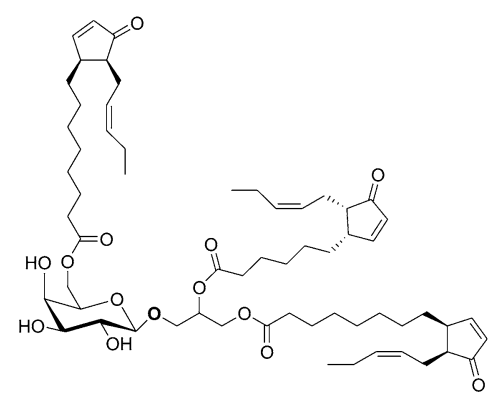

Arabidopside $\mathrm{E}$

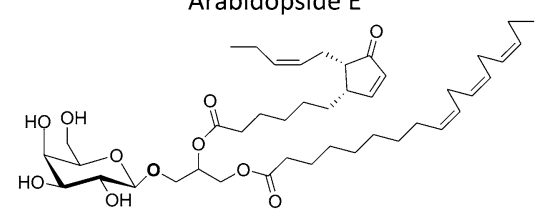

Arabidopside $\mathrm{F}$

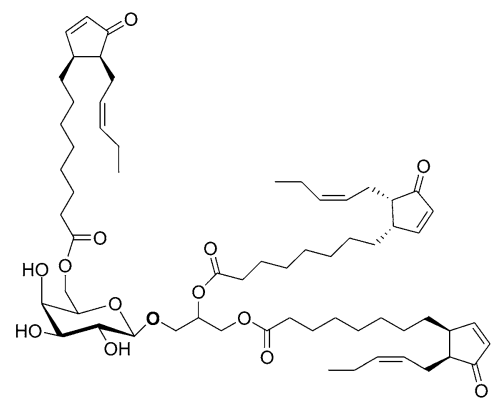

Arabidopside G

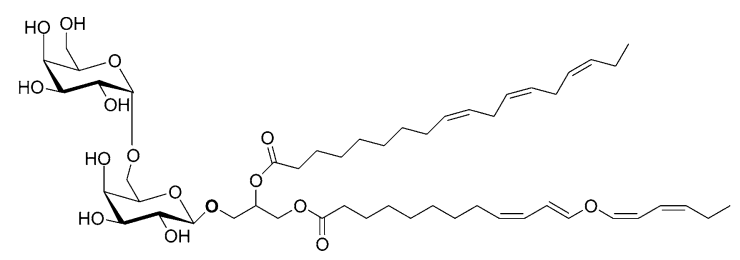

Linolipin C

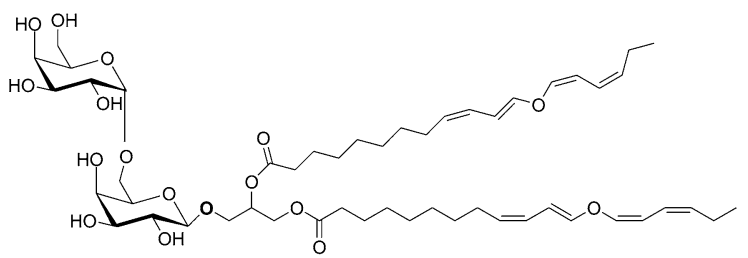

Linolipin D

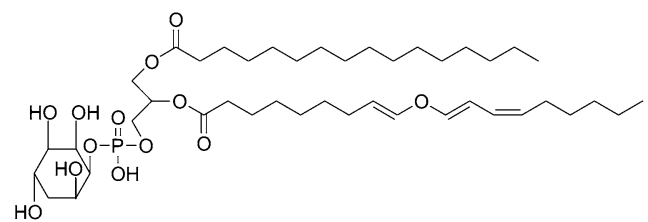

$16: 0$ /colneleic acid - Phosphatidylinositol 
containing at least one divinyl ether residue and more precisely a ( $\omega 5 Z)$-etherolenic acid chain (Chechetkin et al. 2009, 2013). Linolipin A is an oxidized MGDG, containing one $\alpha$-linolenic acid (LA) chain in the $s n-1$ position and one ( $\omega 5 Z$ )-etherolenic acid residue esterified in the $s n-2$ position (Chechetkin et al. 2009). Linolipin C is an oxidized DGDG, containing one $(\omega 5 Z)$-etherolenic acid esterify in the $s n-1$ position and one LA chain in the $s n-2$ position (Chechetkin et al. 2013). Linolipins B and D are respectively an oxidized MGDG and DGDG, both containing two $(\omega 5 Z)$-etherolenic acid residues esterified in the $s n-1$ and $s n-2$ positions (Chechetkin et al. 2009, 2013). Glycerol asymmetric carbon configurations in all described linolipins remain unknown. While linolipin $\mathrm{A}$ is constitutively produced by old flax leaves, levels of linolipins B, C and D dramatically increased after bacterial infection (Chechetkin et al. 2009, 2013).

\section{Other oxidized glycolipids}

Among other oxidized glycolipids, galactolipids containing esterified hydroperoxides, ketols, hydroxides and phytoprostanes were found in mechanically wounded A. thaliana (Ibrahim et al. 2011; Vu et al. 2012; Zhao et al. 2013). In 2013, MGDGs containing esterified traumatin, dinortraumatin and its derivatives were also found to be produced by wounded leaves of A. thaliana, tobacco, cabbage and common bean (Nakashima et al. 2013).

\section{Other esterified oxylipins}

Whereas oxidized glycolipids were increasingly characterized as mentioned above, other esterified oxylipins have been reported in different plant species. In 2003, it was shown that potato tubers contain colneleic acid esterified in phospholipids (Fig. 1) (Fauconnier et al. 2003). In addition, Buseman et al. (2006) reported that wounded A. thaliana leaves not only produce oxidized glycolipids, such as arabidopsides, but also generate OPDA and ketols esterified in phosphatidylglycerol (PG). Vu et al. (2012) highlighted the diversity in oxidized phospholipids produced under stress, with (dn)OPDA, 9-HPOT and 9-HPOD being found esterified in phosphatidylethanolamines, $\mathrm{PG}$ and phosphatidylcholines. Nilsson et al. (2014) confirmed those observations and demonstrated that the hypersensitive response in $A$. thaliana triggers production in leaves of ( $\mathrm{dn}) \mathrm{OPDA}$ containing lipids, such as sulfoquinovosyl diacylglycerol, phosphatidylinositol (PI) and head group acylated PG.

Table 1 Plant species producing (dn)OPDA-containing galactolipids

\begin{tabular}{lll}
\hline Plant species & Family & First discovery \\
\hline Arabidopsis arenosa (L.) Lawalrée & Brassicaceae & Böttcher and Weiler (2007) \\
Arabidopsis halleri (L.) O'Kane \& Al-Shehbaz & Böttcher (2007) \\
Arabidopsis lyrata (L.) O’Kane \& Al-Shehbaz & Nilsson et al. (2015) \\
Arabidopsis petraea (L.) Kolník \& Marhold & Böttcher (2007) \\
Arabidopsis suecia (Fr.) Norrl. & Nilsson et al. (2015) \\
Arabidopsis thaliana (L.) Heynh & Stelmach et al. (2001) \\
Arabidopsis Lasiocarpa (Hook.f. \& Thomson) O.E.Schulz & Nilsson et al. (2015) \\
Arabis pendula L. & Böttcher (2007) \\
Camelina microcarpa Andrz. ex DC. & Böttcher (2007) \\
Capsella rubella (Reut.) Hobk. & Böttcher (2007) \\
$\begin{array}{ll}\text { Erucastrum canariense Webb \& Berthel } \\
\text { Nasturtium officinale R. Br. }\end{array}$ & Pedras and To (2017) \\
Neslia paniculata (L.) Desv. & Pedras and To (2017) \\
$\begin{array}{ll}\text { Olimarabidopsis pumila (Celak.) Al-Shehbaz, O’Kane \& R.A.Price } \\
\text { Melissa officinalis L. }\end{array}$ & Böttcher (2007) \\
Cirsium arverse (L.) Scop. & Nilsson et al. (2015) \\
Ipomoea tricolor Cav. & Zábranská et al. (2012) \\
\hline
\end{tabular}




\section{Oxylipin biosynthesis pathways}

As mentioned previously, oxylipins are structurally diverse compounds produced following enzymatic or non-enzymatic oxidation of polyunsaturated fatty acids. While the present section mainly aims to detail plant esterified oxylipin synthesis pathways, biosynthesis of free oxylipins is described below. For more details, plant free oxylipin biosynthesis pathways are reviewed in Creelman and Mulpuri (2002), Mosblech et al. (2009), Acosta and Farmer (2010), Wasternack and Hause (2013), Griffiths (2015), Ahmad et al. (2016) and Wasternack and Song (2016).

Free oxylipins biosynthesis

Free oxylipins biosynthesis (Fig. 2) is initiated by the action of lipases that hydrolyze fatty acids from membrane lipids such as phospholipids, MGDGs and DGDGs. Among them, linoleic acid (LEA), LA and hexadecatrienoic acid (HTA) are plant substrates for lipoxygenases (LOX) that catalyze oxygen insertion into the fatty acid chain. Those unsaturated fatty acids can also be oxidized by $\alpha$-dioxygenases (DOX) (Hamberg et al. 1999; Stumpe and Feussner 2006; Griffiths 2015; Wang et al. 2018).

Enzymes 9- and 13-LOX are regioselective, catalyzing fatty acid oxidation into fatty acids hydroperoxydes, depending on the oxidation site (Griffiths 2015). Hydroperoxides 13-HPOT and 11-hydroperoxyhexadecatrienoic acid (11-HPHT) produced following 13-LOX oxidation of LA and HTA (Griffiths 2015) are substrates for the enzyme allene oxide synthase (AOS) that transforms them into unstable allene oxides. Those molecules are then spontaneously or enzymatically cyclized to form OPDA and dnOPDA, respectively. It is known that spontaneous cyclization gives a blend of OPDA-enantiomers $(9 R, 13 R$ and $9 S, 13 S)$, while enzymatic cyclization by the allene oxide cyclase (AOC) enzyme only gives the optically pure $9 S, 13 S$ OPDA stereoisomer (Creelman and Mulpuri 2002; Hofmann et al. 2006; Wasternack and Hause 2013; Nilsson et al. 2016; Bjornson et al. 2017). Two different JA synthesis pathways from (dn)OPDA have currently been described (Chini et al. 2018; Howe 2018; Wasternack and Hause 2018). OPDA and dnOPDA can be reduced by OPDA reductase 3 (OPR3) and the products formed are then transformed into JA by $3 \beta$-oxidations or $2 \beta$ - oxidations, respectively (Creelman and Mulpuri 2002; Wasternack and Hause 2013; Ahmad et al. 2016). Surprisingly, an OPR3-independent synthesis pathway for JA has been recently discovered in $A$. thaliana. OPDA and dnOPDA can indeed enter the peroxisome and follow three or two rounds of $\beta$ oxidations, respectively. The product formed then leaves the peroxisome and is reduced in the cytosol by OPDA reductase 2 (OPR2) to form JA (Chini et al. 2018). JA is part of an oxylipin family called jasmonates that includes oxylipins produced enzymatically following LA and HTA acid transformation into JA and its derivatives, such as JA-isoleucine (JA-Ile). Jasmonates have been studied for years and some of them are known to play important developmental and defensive roles (Feussner et al. 1995; Wasternack and Kombrink 2010; Koo 2018). JA derivatives (Ahmad et al. 2016) and some of their precursors (Stintzi et al. 2001; Dave and Graham 2012) are able to modulate gene expression leading to important developmental and defensive changes. For example, they are involved in plant defense against insects (Vijayan et al. 1998), flower development, leaf senescence and seed germination (Ahmad et al. 2016). Biological activities of jasmonates have been extensively studied and were recently reviewed (Wasternack and Strnad 2016, 2018; Huang et al. 2017; Koo 2018; Wasternack and Feussner 2018).

Hydroperoxides 13-HPOT and 11-HPHT are also substrates for hydroperoxide lyase (HPL) that cleaves the $\mathrm{C} 12-\mathrm{C} 13$ bond and produces (3Z)-hexenal and (9Z)-traumatin from 13-HPOT and (3Z)-hexenal and (7Z)-dinortraumatin from 11-HPHT (Vick and Zimmerman 1987; Croft et al. 1993; Nakashima et al. 2013). Recently, it was shown that the initial products of HPL are hemiacetals, unstable compounds that are rapidly transformed into aldehydes and oxoacids (Mukhtarova et al. 2018).

The consecutive action of LOX and divinyl ether synthase (DES) on fatty acids, mainly on LEA and LA, also produces oxidized derivatives called divinyl ethers (Stumpe et al. 2008). Among these compounds, colneleic and colnelenic acids are produced from 9-hydroperoxides of LEA and LA, respectively. Etheroleic and etherolenic acids are, in turn, produced from the 13-hydroperoxides of LEA and LA, respectively (Hamberg 1998). The hydroperoxide fatty acids can also be transformed by other pathways into various other compounds, such as epoxides, epoxy 


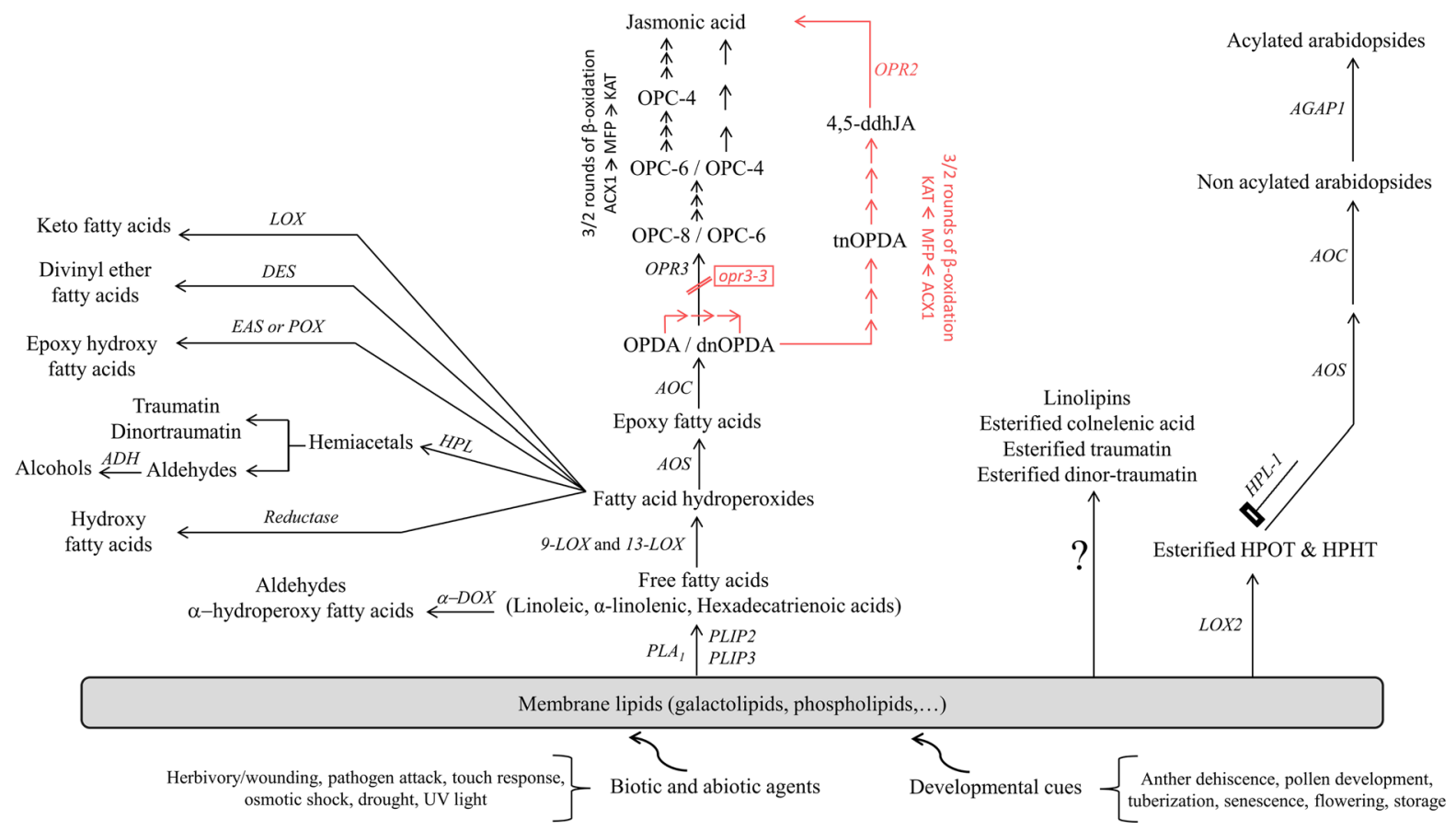

Fig. 2 Biosynthesis pathways of plant free and esterified oxylipins. Following biotic and abiotic stress, free oxylipins are hydrolyzed from membrane complex lipids by lipases. Free unsaturated fatty acids can then be oxidized by diverse enzymes into a wide range of metabolites. Among those, 13- hydroperoxylinolenic acid (13-HPOT) and 11-hydroperoxyhexadecatrienoic acid (11-HPHT) can be submitted to the subsequent action of allene oxide synthase (AOS) and allene oxide cyclase (AOC) and be transformed into 12-oxo-phytodienoic acid (OPDA) and 12-dinor-oxo-phytodienoic acid (dnOPDA), respectively. Two pathways of jasmonic acid biosynthesis from OPDA/dnOPDA are shown. OPDA/dnOPDA can be reduced by OPDA reductase 3 (OPR3) and then undergo three/two rounds of $\beta$-oxidation (in black). An alternative pathway (in red) was recently described by (Chini et al. 2018). In opr3-3 plants, OPDA/dnOPDA directly undergo three/two rounds of $\beta$ oxidation and are then reduced to jasmonic acid by OPDA reductase 2 (OPR2). Following biotic and abiotic stress, membrane galactolipids can also be directly oxidized by

alcohols, ketols, hydroxy fatty acids and aldehydes (Hamberg 1998).

Esterified oxylipins biosynthesis and subcellular localization

Two main hypotheses are currently proposed to explain the biosynthesis of esterified oxylipins. Firstly, it has been suggested that free oxylipins could be produced from free fatty acids and then subsequently be esterified into complex lipids. Alternatively, fatty lipoxygenase 2 (LOX2) into esterified HPOT and HPHT. Subsequent action of AOS and AOC on those products leads to non-acylated arabidopsides formation. Acylated galactolipid associated phospholipase 1 (AGAP1) can then catalyze the transfer of (dn)OPDA from galactolipids to the galactose moiety of other arabidopsides, forming acylated arabidopsides. Other esterified oxylipins such as linolipins have also been described, but their biosynthesis remains unknown. ACX1 (acyl-coenzyme A oxidase 1), ADH (alcohol dehydrogenase), DES (divinyl ether synthase), DOX ( $\alpha$-dioxygenase), EAS (epoxy alcohol synthase), HPL (hydroperoxide lyase), KAT (3-ketoacyl-coenzyme A oxidase), LOX (lipoxygenase), MFP (multifunctional protein), OPC-4 (4-(3-oxo-2-(pent-2-enyl)cyclopentyl)butanoic acid), OPC-6 (6-(3-oxo-2-(pent-2-enyl)cyclopentyl)hexanoic acid), OPC-8 (8-(3-oxo-2-(pent-2-enyl)cyclopentyl)octanoic acid), PLA 1 (phospholipase A1), PLIP2 (plastid lipase 2), PLIP3 (plastid lipase 3), POX (peroxygenase), tnOPDA (tetranor-OPDA), 4,5-ddhJA (4,5-didehydro-jasmonic acid). (Color figure online)

acids esterified into complex lipids may be directly transformed into oxylipins (Stelmach et al. 2001; Buseman et al. 2006; Chechetkin et al. 2009, 2013). In general, LOX enzymes responsible for the first transformation step of fatty acids into oxylipins are thought to only use free fatty acids and not esterified substrates (Gardner 1991; Babenko et al. 2017). However, a few specific LOX have been reported to use esterified substrates such as phospholipids and galactolipids in vitro (Feussner et al. 1995; Nakashima et al. 2011; Meyer et al. 2013); for example, soybean 
LOX1 was able to oxidize MGDG (Nakashima et al. 2011).

Different studies have focused on the biosynthesis pathways of (dn)OPDA-containing esterified oxylipins in A. thaliana and these aspects will be discussed here. Unfortunately, there is still no study available on the synthesis of other esterified oxylipins, such as linolipins.

\section{Arabidopside synthesis}

As arabidopsides are oxidized MGDG and DGDG, it was firstly suggested that these compounds were produced following oxidation of plant chloroplast membrane galactolipids (Stelmach et al. 2001). Free $(\mathrm{dn})$ OPDA could then be rapidly esterified into chloroplastic MGDG and DGDG, or unsaturated fatty acids in MGDG and DGDG could be directly transformed into (dn)OPDA by LOX, AOS and AOC action (Stelmach et al. 2001; Buseman et al. 2006). Notably, the second proposal was supported by the discovery in 2012 that galactolipid fatty acid chains can be directly oxidized. A. thaliana leaves incubated in ${ }^{18} \mathrm{O}$-labelled water before being wounded, did not lead to the formation of ${ }^{18} \mathrm{O}$-labelled arabidopsides. This experiment proved that esterified fatty acids were not hydrolyzed, oxidized and re-esterified. In addition, arabidopsides are quickly formed in completely disrupted cells without free fatty acid formation, which favors a production mechanism from esterified fatty acids (Nilsson et al. 2012). As described above, OPDA production starts with LOX oxygenation of fatty acids. A. thaliana possesses six LOX isoforms, four of them are 13-LOX (LOX2, LOX3, LOX4, LOX6) and two are 9-LOX (LOX1, LOX5) (Wasternack and Hause 2013). Interestingly, LOX2 is largely implicated in (dn)OPDA-containing esterified oxylipin synthesis, as production of arabidopsides A, B and C in wounded plants decreases dramatically in Arabidopsis lox2-1 mutants compared to wild type plants (Glauser et al. 2009; Zoeller et al. 2012; Nilsson et al. 2016). As the increase in HPL expression leads to less arabidopside accumulation, it was suggested than this enzyme competes with AOS for esterified fatty acid hydroperoxides (Nilsson et al. 2016). These results are consistent with the fact that $A$. thaliana Columbia 0 wild type, which does not express any functional HPL, produces high quantities of arabidopsides (Duan et al. 2005; Chehab et al. 2008; Nilsson et al. 2016). Finally, since ( $\mathrm{dn}$ )OPDA esterified in galactolipids and formed after freeze-thawing in A. thaliana are only present as $S, S$ stereoisomers, it was proposed that allene oxide cyclization does not occur spontaneously but enzymatically by AOC action, suggesting that freezethawing triggers the activation of LOX2, AOS and AOC that are likely already synthesized. However, $A$. thaliana possesses four AOC isoforms and it is not known if one of them or all of them are involved in this transformation (Nilsson et al. 2016).

MGDGs containing one oxidized chain acylated on the galactose $6^{\prime}$-hydroxyl group, such as arabidopsides $\mathrm{E}$ and G, were also reported (Andersson et al. 2006; Kourtchenko et al. 2007; $\mathrm{Vu}$ et al. 2014). In A. thaliana, non-acylated (dn)OPDA containing MGDG and DGDG are rapidly produced upon stress and peak after approximatively $5 \mathrm{~min}$. The presence of those molecules then decreases and oxidized acyl MGDGs are produced and reach a maximum approximatively 30 min after stress ( Vu et al. 2014; Nilsson et al. 2016). Actually, (dn)OPDA esterified in galactolipids is transferred to the galactose moiety of other MGDGs (Vu et al. 2014; Nilsson et al. 2015) by acylated galactolipid associated phospholipase 1 (AGAP1), forming OPDA-acylated MGDG (Nilsson et al. 2015). Mutants of $A$. thaliana with an AGAPI knockout are unable to produce oxidized and non-oxidized acyl MGDGs (Nilsson et al. 2015).

\section{Localization of arabidopsides}

It has been suggested that arabidopsides are mainly localized in chloroplast membranes (Böttcher and Weiler 2007), since galactolipids are a major constituent of these membranes (Dörmann and Benning 2002). Böttcher and Weiler (2007) found high quantities of esterified (dn)OPDA in thylakoid membranes but low quantities in the chloroplast envelope membranes. AOS and AOC, the two enzymes responsible for fatty acid hydroperoxide transformation into (dn)OPDA are localized in chloroplasts, supporting this hypothesized location (Wasternack and Hause 2013). However, it has not been established if the OPDA located in chloroplasts is esterified in galactolipids. It is also not known if those molecules can be found in other plant organelles, or if they are transferred from chloroplast membranes to other plant cell organelle. In this context, it has been shown that under specific conditions, such as phosphate 
starvation, non-oxidized DGDG can be transferred from chloroplast membranes to non-plastidial membranes such as mitochondrial membranes (Jouhet et al. 2004) and plasma membrane (Andersson et al. 2005; Tjellström et al. 2008). As it is known that phosphate deprivation induces LOX2 expression in A. thaliana leaves (Khan et al. 2016) and that this enzyme is implicated in arabidopside synthesis (Glauser et al. 2009), this same trafficking process could occur for arabidopsides. It is known that any change in plant plasma membrane composition can affect its integrity and its wide range of functions (Deleu et al. 2014). Therefore, arabidopside trafficking to the plasma membrane could have many effects on plant physiology. Due to their particular structure, arabidopsides should have different interfacial properties compared to plant plasma membrane lipids. Arabidopside presence in this membrane might modify lipid organization and plasma membrane properties such as fluidity and permeability. A wide range of proteins are present in the plasma membrane, including some involved in signaling functions. As a result, modifications in the lipid environment of these proteins might alter their activities and so influence signaling pathways, possibly those involved in plant defense mechanisms.

\section{Function of esterified oxylipins}

Although specific roles have not been assigned to esterified oxylipins, they are thought to be involved in plant defense and developmental processes (Fig. 3).

Esterified oxylipin involvement in plant defense and developmental processes

Many insights about esterified oxylipins, such as arabidopsides and linolipins, highlight their probable involvement in plant defense mechanisms. Firstly, these molecules are largely produced under stress conditions. For example, A. thaliana esterified oxylipins peak under a wide range of different biotic and abiotic stresses, such as wounding, freezing and pathogen infection (Buseman et al. 2006; Böttcher and Weiler 2007; Kourtchenko et al. 2007; Glauser et al. 2008, 2009; Chechetkin et al. 2009, 2013; Koo et al. 2009; Vu et al. 2012, 2015). Moreover, upon wounding, arabidopsides not only accumulate in wounded leaves but also in distal unwounded leaves of the same plant (Glauser et al. 2009). In addition, the A. thaliana esterified oxylipin profile is dependent on the nature of the stress. For example, wounding induces much more oxidized MGDG production than freezing ( $\mathrm{Vu}$ et al. 2012). Moreover, the A. thaliana lox2-1 mutant, which is defective in arabidopside production, is more susceptible to herbivory by larvae of the insect Spodoptera littoralis than wild type plants (Glauser et al. 2009). In the case of linolipins, a recent study showed that their production in flax leaves can be induced by 24-epibrassinolide (EPB) (Fedina et al. 2017), a plant steroid hormone implicated in plant stress responses (Lee et al. 2018). Linolipin production following Pectobacterium atrosepticum infection of leaves pretreated with EPB was greatly increased compared to non-treated leaves, suggesting an hormonal regulation of esterified oxylipin production during plant bacterial infection (Fedina et al. 2017).

It has also been suggested that esterified oxylipins might play a role in plant development. As an example, linolipin profiles are different depending on the plant developmental stage. These molecules were not detected in young flax leaves, at day 23 of culture, with production starting at a later stage of development, from day 35 of culture, and reaching a concentration of $71 \mathrm{nmol} / \mathrm{g}$ FW (Chechetkin et al. 2009, 2013).

Indirect functions of esterified oxylipins

It has been suggested that esterified oxylipins might act as a pool of free oxylipins that could be released when necessary (Stelmach et al. 2001; Ohashi et al. 2005; Dave and Graham 2012). This hypothesis was supported by the discovery of two $A$. thaliana phospholipases, pPLAII $\alpha$ and AtPLAI, able to release free OPDA from oxidized glycolipids (Yang et al. 2007, 2012). In the same way, arabidopside levels are increased in some A. thaliana mutants with reduced pPLAII $\alpha$ expression (Davoine et al. 2017). (dn)OPDA containing MGMG and DGMG found in, for example, A. thaliana were proposed as by-products formed after free oxylipins hydrolysis from oxidized MGDG and DGDG (Glauser et al. 2008). As such, released (dn)OPDA could be used as a substrate for JA production, an essential compound in the regulation of plant developmental, physiological and defense mechanisms (Wasternack and Strnad 2016, 2018; Huang et al. 2017; Koo 2018; Wasternack and 


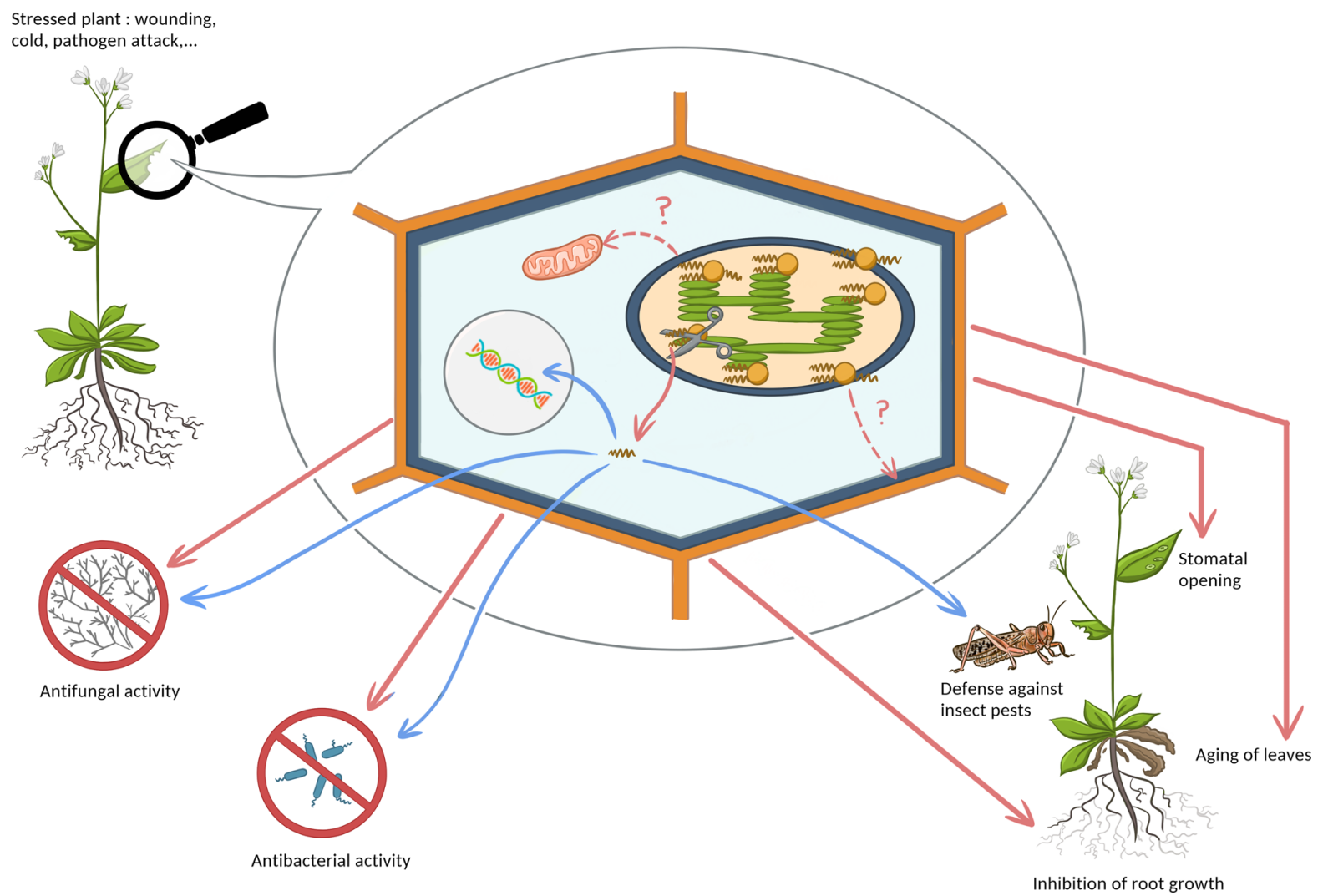

Fig. 3 Potential functions of esterified oxylipins in plants. Esterified oxylipins are largely produced under biotic and abiotic stress such as wounding, pathogen infection and low temperature treatment. Among them, oxidized galactolipids such as arabidopsides are likely formed in chloroplast membranes. Esterified oxylipins may have direct (red arrows) and indirect (blue arrows) functions. Potential direct functions of those molecules include modifications of chloroplast function,

Feussner 2018). Free OPDA might also directly modulate gene expression, as this compound has been shown to induce JA-independent responses. OPDA is able to activate gene expression, leading to various responses independent of JA-Ile (Wasternack and Strnad 2016). OPDA is notably involved in plant fungal resistance (Stintzi et al. 2001), in drought stress responses (Savchenko et al. 2014) and in defense processes during plant-insect interactions (Schafer et al. 2011). Moreover, OPDA and abscisic acid were shown to cause inhibition of seed germination, though this effect was previously attributed to JA (Dave et al. 2011; Dave and Graham 2012). However, little is known about OPDA signaling as this molecule is not able to bind the co-receptor complex allowing JA-Ile plant senescence, stomatal opening, inhibition of root growth, and antifungal and antibacterial activities. Esterified oxylipins may also be transferred to plasma and mitochondrial membranes, and thus modify membrane properties. Indirect functions have also been suggested for esterified oxylipins, including modulation of gene expression and inhibition of pathogen growth (pests, bacteria and fungi). Drawing by Carolina Levicek. (Color figure online)

perception (Arnold et al. 2016). Recently, OPDA conjugated with isoleucine (OPDA-Ile) was described in A. thaliana (Floková et al. 2016) and its ability to induce OPDA-specific gene expression was confirmed (Arnold et al. 2016). In vitro studies recently showed that an isoleucine conjugate of LA can be used as a substrate for OPDA-Ile formation (Uchiyama et al. 2018); however, the mechanisms behind the perception of this molecule have not been determined.

Oxidized MGDG and DGDG containing dihydroOPDA and dihydroJA were also detected in Cirsium arvense infected with a foliar endophyte, $C$. cochlioides. As dihydroOPDA is an intermediate of OPDA transformation into JA, it was suggested that with esterified OPDA further metabolism is possible. 
Moreover, as dihydroJA was detected but not free jasmonates, the authors suggested that the latter ones may have been synthesized and that endophyte infection may have cause their further sequestration (Hartley et al. 2015).

Linolipins consisting of etherolenic acid esterified into MGDG or DGDG can generate free etherolenic acid and its degradation product, $(E)$-hexenal, known to inhibit flax seed germination and root development (Chechetkin et al. 2009, 2013). Moreover, some divinyl ethers possess antifungal and/or antibacterial activities against plant pathogens (Prost et al. 2005), supporting the hypothesis that linolipins could act as a storage of free colnelenic acid that could be released rapidly when needed for biological activities.

\section{Direct functions of esterified oxylipins}

It has been suggested that plant esterified oxylipins are not only used as a pool of free oxylipins, but that the whole molecule per se could have a direct function. Notably, in vitro studies showed that some of them could decrease pathogen growth, such as arabidopside E with $P$. syringae, while MGDG and free OPDA had no significant effect at the same concentration (Andersson et al. 2006). Additionally, arabidopsides $\mathrm{E}$ and $\mathrm{G}$ both decrease growth of $B$. cinerea in vitro (Kourtchenko et al. 2007), and arabidopside A possesses direct antifungal properties against $A l$ ternaria brassicicola, Leptosphaeria maculans and Sclerotinia sclerotiorum (Pedras and To 2017).

Plant esterified oxylipins may also have developmental roles, as arabidopsides A, B, D and F are able to inhibit cress root growth (Hisamatsu et al. 2005; Shigemori et al. 2006). Arabidopsides may have a role in senescence as those molecules accumulate in $A$. thaliana mutants showing early leaf senescence (Xiao et al. 2010; $\mathrm{Hu}$ et al. 2018). In the same way, arabidopsides A, B, C, D, and F have a senescence promoting effect on leaves of Avena sativa L., cv. zenshin. At the same concentration, the senescence promoting effect of oxidized DGDGs is stronger than oxidized MGDGs. Oxidized DGDGs are in fact able to induce senescence in a similar way to JA, OPDA and methyl jasmonate, a well-known senescence promotor (Hisamatsu et al. 2006; Shigemori et al. 2011). In addition, an OPDA-containing MGMG isolated from I. tricolor was shown to possess stomatal opening properties in Commelina communis L. (Ohashi et al. 2005).

All these studies highlight a possible direct involvement of esterified oxylipins in plant stress responses and developmental processes. However, it should be noted that biological functions described here were investigated using purified molecules obtained from plant extracts whose chirality was not fully determined. As arabidopside D was reported to be a racemic blend of two enantiomers (Hisamatsu et al. 2005), it is possible that some arabidopsides exist in stereoisomer mixtures and that distinct enantiomers possess different biological activities. Total synthesis of arabidopsides has not been done yet, and esterified oxylipin extraction and purification remain challenging as low molecule yields are obtained. This presents an obstacle to certain biological studies such as inhibition of plant pathogen growth, study of arabidopsides and plant membrane lipid interactions and the study of biological activities of different stereoisomers.

As mentioned above, oxidized galactolipids in $A$. thaliana are likely formed in thylakoid membranes upon MGDG and DGDG oxidation (Böttcher and Weiler 2007). Lipids of the latter are part of photosystems I and II of the light harvesting complex II and are hence essential for plant photosynthesis and growth (Boudière et al. 2014; Kelly et al. 2016). A. thaliana mutants unable to synthesize DGDG show a reduced photosynthetic ability and an altered chloroplast morphology, suggesting that lipid integrity is essential for its correct function (Lin et al. 2016). Arabidopside production in these membranes, notably upon stress, might modify membrane properties. Since photosynthesis ability of chloroplasts containing arabidopsides has not been studied yet, it represents an exciting avenue for future investigation.

\section{Conclusion}

Plant esterified oxylipins were only reported in a restricted number of plant species. Those molecules have been mainly described in Arabidopsis species, where many galactolipids and phospholipids containing esterified (dn)OPDA have been reported. However, the number of recent publications describing esterified oxylipins in plant species and different plant organs is increasing. Notably, esterified oxylipins have 
not only been found in other species of the Brassicaceae but also in other families such as Lamiaceae, Asteraceae, Convolvulaceae and Linaceae. The recent literature suggests that esterified oxylipins may be widespread metabolites in plants and that those molecules may have numerous functions that have not been identified yet. Those molecules seem to play important roles in plant stress responses and developmental processes. We propose that esterified oxylipins are considered as rare metabolites because analytical methods did not allow routine analysis of these molecules up until recently. New methods, including direct infusion mass spectrometry and HPLC-MS/ MS, have allowed an easy identification and quantification of a large number of these esterified oxylipins; however, these methods do not provide information about their stereochemistry. Esterified oxylipins are produced under specific conditions such as following biotic and abiotic stresses, at precise plant developmental stages and in particular plant organs. Besides these conditions, it is possible that esterified oxylipins are not detected in plants because their levels are lower than analytical detection limits. Future investigation on their biological functions should open the way to identify the importance of these metabolites in plant developmental processes and defense mechanisms.

Acknowledgements M.D. and L.L. thank the Fonds National de la Recherche Scientifique from Belgium (FRS-FNRS) for their positions as Senior Research Associates and for financial support via Grants PDR T.1003.14 and CDR J.0114.18 and J.0086.18. F.OA. thanks the University of Liège for financial support for the study of esterified oxylipins, and more specifically arabidopsides, via the BEIPD Marie Curie Cofund grant. The authors thanks the University of Liège for financial support via Action de Recherche Concertée-Project FIELD. This paper was published with the support of the Belgian University Foundation (Fondation Universitaire de Belgique).

\section{Compliance with ethical standards}

Conflict of interest The authors declare that they have no conflict of interest.

Open Access This article is distributed under the terms of the Creative Commons Attribution 4.0 International License (http:// creativecommons.org/licenses/by/4.0/), which permits unrestricted use, distribution, and reproduction in any medium, provided you give appropriate credit to the original author(s) and the source, provide a link to the Creative Commons license, and indicate if changes were made.

\section{References}

Acosta IF, Farmer EE (2010) Jasmonates. Arab B. https://doi. org/10.1199/tab.0129

Ahmad P, Rasool S, Gul A et al (2016) Jasmonates: multifunctional roles in stress tolerance. Front Plant Sci. https:// doi.org/10.3389/fpls.2016.00813

Andersson MX, Larsson KE, Tjellström H et al (2005) Phosphate-limited oat: the plasma membrane and the tonoplast as major targets for phospholipid-to-glycolipid replacement and stimulation of phospholipases in the plasma membrane. J Biol Chem 280:27578-27586. https://doi.org/ 10.1074/jbc.M503273200

Andersson MX, Hamberg M, Kourtchenko O et al (2006) Oxylipin profiling of the hypersensitive response in Arabidopsis thaliana. Formation of a novel oxo-phytodienoic acid-containing galactolipid, arabidopside E. J Biol Chem 281:31528-31537. https://doi.org/10.1074/jbc. M604820200

Andreou A, Brodhun F, Feussner I (2009) Biosynthesis of oxylipins in non-mammals. Prog Lipid Res 48:148-170. https://doi.org/10.1016/j.plipres.2009.02.002

Arnold MD, Gruber C, Floková K et al (2016) The recently identified isoleucine conjugate of cis-12-oxo-phytodienoic acid is partially active in cis-12-oxo-phytodienoic acidspecific gene expression of Arabidopsis thaliana. PLoS ONE 11:e0162829. https://doi.org/10.1371/journal.pone. 0162829

Babenko LM, Shcherbatiuk MM, Skaterna TD, Kosakivska IV (2017) Lipoxygenases and their metabolites in formation of plant stress tolerance. Ukr Biochem J 89:5-21. https:// doi.org/10.15407/ubj89.01.005

Bjornson M, Balcke GU, Xiao Y et al (2017) Integrated omics analyses of retrograde signaling mutant delineate interrelated stress-response strata. Plant J 91:70-84. https://doi. org/10.1111/tpj.13547

Blée E (2002) Impact of phyto-oxylipins in plant defense. Trends Plant Sci 7:315-321. https://doi.org/10.1016/ S1360-1385(02)02290-2

Böttcher C (2007) Studies on the biology of free and esterified phytodienoic acids. Ruhr-University Bochum, Germany

Böttcher C, Weiler EW (2007) cyclo-Oxylipin-galactolipids in plants: occurrence and dynamics. Planta 226:629-637. https://doi.org/10.1007/s00425-007-0511-5

Boudière L, Michaud M, Petroutsos D et al (2014) Glycerolipids in photosynthesis: composition, synthesis and trafficking. Biochim Biophys Acta Bioenergy 1837:470-480. https:// doi.org/10.1016/j.bbabio.2013.09.007

Buseman CM, Tamura P, Sparks AA et al (2006) Wounding stimulates the accumulation of glycerolipids containing oxophytodienoic acid and dinor-oxophytodienoic acid in Arabidopsis leaves. Plant Physiol 142:28-39. https://doi. org/10.1104/pp.106.082115

Chechetkin IR, Mukhitova FK, Blufard AS et al (2009) Unprecedented pathogen-inducible complex oxylipins from flax-linolipins A and B. FEBS J 276:4463-4472. https://doi.org/10.1111/j.1742-4658.2009.07153.x

Chechetkin IR, Blufard AS, Khairutdinov BI et al (2013) Isolation and structure elucidation of linolipins C and D, complex oxylipins from flax leaves. Phytochemistry 
96:110-116. https://doi.org/10.1016/j.phytochem.2013.08. 010

Chehab EW, Kaspi R, Savchenko T et al (2008) Distinct roles of jasmonates and aldehydes in plant-defense responses. PLoS ONE 3:122. https://doi.org/10.1371/journal.pone. 0001904

Chini A, Monte I, Zamarreño AM et al (2018) An OPR3-independent pathway uses 4,5-didehydrojasmonate for jasmonate synthesis. Nat Chem Biol 14:171-178. https://doi. org/10.1038/nchembio. 2540

Creelman RA, Mulpuri R (2002) The oxylipin pathway in Arabidopsis. Arab B. https://doi.org/10.1199/tab.0012

Croft K, Juttner F, Slusarenko AJ (1993) Volatile products of the lipoxygenase pathway evolved from Phaseolus vulgaris (L.) leaves inoculated with Pseudomonas syringae pv phaseolicola. Plant Physiol 101:13-24. https://doi.org/10. 1104/pp.101.1.13

Dave A, Graham IA (2012) Oxylipin signaling: a distinct role for the jasmonic acid precursor cis- $(+)-12$-oxo-phytodienoic acid (cis-OPDA). Front Plant Sci 3:122. https://doi. org/10.3389/fpls.2012.00042

Dave A, Hernández ML, He Z et al (2011) 12-Oxo-phytodienoic acid accumulation during seed development represses seed germination in Arabidopsis. Plant Cell 23:583-599. https:// doi.org/10.1105/tpc.110.081489

Davoine C, Abreu IN, Khajeh K et al (2017) Functional metabolomics as a tool to analyze mediator function and structure in plants. PLoS ONE 12:e0179640. https://doi. org/10.1371/journal.pone.0179640

Deleu M, Crowet JM, Nasir MN, Lins L (2014) Complementary biophysical tools to investigate lipid specificity in the interaction between bioactive molecules and the plasma membrane: a review. Biochim Biophys Acta 1838:3171-3190. https://doi.org/10.1016/j.bbamem.2014. 08.023

Dörmann P, Benning C (2002) Galactolipids rule in seed plants. Trends Plant Sci 7:112-118. https://doi.org/10.1016/ S1360-1385(01)02216-6

Duan H, Huang M-Y, Palacio K, Schuler MA (2005) Variations in CYP74B2 (Hydroperoxide Lyase) gene expression differentially affect hexenal signaling in the Columbia and Landsberg erecta ecotypes of Arabidopsis. Plant Physiol 139:1529-1544. https://doi.org/10.1104/pp.105.067249

Fauconnier M-L, Williams TD, Marlier M, Welti R (2003) Potato tuber phospholipids contain colneleic acid in the 2-position. FEBS Lett 538:155-158. https://doi.org/10. 1016/S0014-5793(03)00171-6

Fauconnier M-L, Rojas-Beltran J, Dupuis B et al (2008) Changes in oxylipin synthesis after Phytophthora infestans infection of potato leaves do not correlate with resistance. Plant Physiol Biochem 46:823-831. https://doi.org/10. 1016/j.plaphy.2008.04.010

Fedina EO, Yarin AY, Blufard AS, Chechetkin IR (2017) Brassinosteroid-induced accumulation of complex oxylipins in flax leaves. Biochem (Moscow) Suppl Ser A Membr Cell Biol 11:301-303. https://doi.org/10.1134/ S1990747817040031

Feussner I, Wasternack C, Kindl H, Kühn H (1995) Lipoxygenase-catalyzed oxygenation of storage lipids is implicated in lipid mobilization during germination. Proc Natl Acad
Sci USA 92:11849-11853. https://doi.org/10.1073/pnas. 92.25.11849

Floková K, Feussner K, Herrfurth C et al (2016) A previously undescribed jasmonate compound in flowering Arabidopsis thaliana-the identification of cis-(+)-OPDA-Ile. Phytochemistry 122:230-237. https://doi.org/10.1016/j. phytochem.2015.11.012

Gardner HW (1991) Recent investigations into the lipoxygenase pathway of plants. Biochim Biophys Acta (BBA) Lipids Lipid Metab 1084:221-239. https://doi.org/10.1016/00052760(91)90063-n

Glauser G, Grata E, Rudaz S, Wolfender J-L (2008) High-resolution profiling of oxylipin-containing galactolipids in Arabidopsis extracts by ultra-performance liquid chromatography/time-of-flight mass spectrometry. Rapid Commun Mass Spectrom 22:3154-3160. https://doi.org/ $10.1002 / \mathrm{rcm} .3716$

Glauser G, Dubugnon L, Mousavi SAR et al (2009) Velocity estimates for signal propagation leading to systemic jasmonic acid accumulation in wounded Arabidopsis. J Biol Chem 284:34506-34513. https://doi.org/10.1074/jbc. M109.061432

Göbel C, Feussner I (2009) Methods for the analysis of oxylipins in plants. Phytochemistry 70:1485-1503. https://doi.org/ 10.1016/j.phytochem.2009.07.040

Grebner W, Stingl NE, Oenel A et al (2013) Lipoxygenase6dependent oxylipin synthesis in roots is required for abiotic and biotic stress resistance of Arabidopsis. Plant Physiol 161:2159-2170. https://doi.org/10.1104/pp.113.214544

Griffiths G (2015) Biosynthesis and analysis of plant oxylipins. Free Radic Res 49:565-582. https://doi.org/10.3109/ 10715762.2014 .1000318

Hamberg M (1998) A pathway for biosynthesis of divinyl ether fatty acids in green leaves. Lipids 33:1061-1071. https:// doi.org/10.1007/s11745-998-0306-7

Hamberg M, Hamberg G (1996) 15(R)-hydroxylinoleic acid, an oxylipin from oat seeds. Phytochemistry 42:729-732. https://doi.org/10.1016/0031-9422(96)00059-3

Hamberg M, Sanz A, Castresana C (1999) $\alpha$-Oxidation of fatty acids in higher plants. J Biol Chem 274:24503-24513. https://doi.org/10.1074/jbc.274.35.24503

Hartley SE, Eschen R, Horwood JM et al (2015) Infection by a foliar endophyte elicits novel arabidopside-based plant defence reactions in its host, Cirsium arvense. New Phytol 205:816-827. https://doi.org/10.1111/nph.13067

Hisamatsu Y, Goto N, Hasegawa K, Shigemori H (2003) Arabidopsides A and B, two new oxylipins from Arabidopsis thaliana. Tetrahedron Lett 44:5553-5556. https://doi.org/ 10.1016/S0040-4039(03)01148-1

Hisamatsu Y, Goto N, Sekiguchi M et al (2005) Oxylipins arabidopsides $\mathrm{C}$ and $\mathrm{D}$ from Arabidopsis thaliana. J Nat Prod 68:600-603. https://doi.org/10.1021/np0495938

Hisamatsu Y, Goto N, Hasegawa K, Shigemori H (2006) Senescence-promoting effect of Arabidopside A. Zeitschrift für Naturforsch C 61:363-366. https://doi.org/10. 1515/znc-2006-5-611

Hofmann E, Zerbe P, Schaller F (2006) The crystal structure of Arabidopsis thaliana allene oxide cyclase: insights into the oxylipin cyclization reaction. Plant Cell Online 18:3201-3217. https://doi.org/10.1105/tpc.106.043984 
Howe GA (2018) Plant hormones: metabolic end run to jasmonate. Nat Chem Biol 14:109-110. https://doi.org/10. 1038/nchembio. 2553

Hu T-H, Lung S-C, Ye Z-W, Chye M-L (2018) Depletion of Arabidopsis ACYL-COA-BINDING PROTEIN3 affects fatty acid composition in the phloem. Front Plant Sci. https://doi.org/10.3389/fpls.2018.00002

Huang H, Liu B, Liu L, Song S (2017) Jasmonate action in plant growth and development. J Exp Bot 68:1349-1359. https:// doi.org/10.1093/jxb/erw495

Ibrahim A, Schütz A-L, Galano J-M et al (2011) The alphabet of galactolipids in Arabidopsis thaliana. Front Plant Sci. https://doi.org/10.3389/fpls.2011.00095

Jouhet J, Maréchal E, Baldan B et al (2004) Phosphate deprivation induces transfer of DGDG galactolipid from chloroplast to mitochondria. J Cell Biol 167:863-874. https://doi.org/10.1083/jcb.200407022

Kelly AA, Kalisch B, Hölzl G et al (2016) Synthesis and transfer of galactolipids in the chloroplast envelope membranes of Arabidopsis thaliana. Proc Natl Acad Sci 113:10714-10719. https://doi.org/10.1073/pnas. 1609184113

Khan GA, Vogiatzaki E, Glauser G, Poirier Y (2016) Phosphate deficiency induces the jasmonate pathway and enhances resistance to insect herbivory. Plant Physiol 171:632-644. https://doi.org/10.1104/pp.16.00278

Koo AJ (2018) Metabolism of the plant hormone jasmonate: a sentinel for tissue damage and master regulator of stress response. Phytochem Rev 17:51-80. https://doi.org/10. 1007/s11101-017-9510-8

Koo AJK, Gao X, Daniel Jones A, Howe GA (2009) A rapid wound signal activates the systemic synthesis of bioactive jasmonates in Arabidopsis. Plant J 59:974-986. https://doi. org/10.1111/j.1365-313X.2009.03924.X

Kourtchenko O, Andersson MX, Hamberg M et al (2007) Oxophytodienoic acid-containing galactolipids in Arabidopsis: jasmonate signaling dependence. Plant Physiol 145:1658-1669. https://doi.org/10.1104/pp.107.104752

Lee JH, Lee J, Kim H et al (2018) Brassinosteroids regulate glucosinolate biosynthesis in Arabidopsis thaliana. Physiol Plant. https://doi.org/10.1111/ppl.12691

Lin Y-T, Chen L-J, Herrfurth C et al (2016) Reduced biosynthesis of digalactosyldiacylglycerol, a major chloroplast membrane lipid, leads to oxylipin overproduction and phloem cap lignification in Arabidopsis. Plant Cell 28:219-232. https://doi.org/10.1105/tpc.15.01002

Mariutto M, Fauconnier M-L, Ongena M et al (2014) Reprogramming of fatty acid and oxylipin synthesis in rhizobacteria-induced systemic resistance in tomato. Plant Mol Biol 84:455-467. https://doi.org/10.1007/s11103013-0144-y

Meyer D, Herrfurth C, Brodhun F, Feussner I (2013) Degradation of lipoxygenase-derived oxylipins by glyoxysomes from sunflower and cucumber cotyledons. BMC Plant Biol 13:177. https://doi.org/10.1186/1471-2229-13-177

Miersch O, Weichert H, Stenzel I et al (2004) Constitutive overexpression of allene oxide cyclase in tomato (Lycopersicon esculentum cv. Lukullus) elevates levels of some jasmonates and octadecanoids in flower organs but not in leaves. Phytochemistry 65:847-856. https://doi.org/10. 1016/j.phytochem.2004.01.016
Mosblech A, Feussner I, Heilmann I (2009) Oxylipins: structurally diverse metabolites from fatty acid oxidation. Plant Physiol Biochem 47:511-517. https://doi.org/10.1016/j. plaphy.2008.12.011

Mukhtarova LS, Brühlmann F, Hamberg M et al (2018) Plant hydroperoxide-cleaving enzymes (CYP74 family) function as hemiacetal synthases: structural proof of hemiacetals by NMR spectroscopy. Biochim Biophys Acta Mol Cell Biol Lipids 1863:1316-1322. https://doi.org/10.1016/j.bbalip. 2018.08.011

Nakashima A, Iijima Y, Aoki K et al (2011) Monogalactosyl diacylglycerol is a substrate for lipoxygenase: its implications for oxylipin formation directly from lipids. J Plant Interact 6:93-97. https://doi.org/10.1080/17429145.2010. 544767

Nakashima A, von Reuss SH, Tasaka H et al (2013) Traumatinand dinortraumatin-containing galactolipids in Arabidopsis. J Biol Chem 288:26078-26088. https://doi.org/10. 1074/jbc.M113.487959

Nilsson AK, Fahlberg P, Ellerström M, Andersson MX (2012) Oxo-phytodienoic acid (OPDA) is formed on fatty acids esterified to galactolipids after tissue disruption in Arabidopsis thaliana. FEBS Lett 586:2483-2487. https://doi. org/10.1016/j.febslet.2012.06.010

Nilsson AK, Johansson ON, Fahlberg P et al (2014) Formation of oxidized phosphatidylinositol and 12-oxo-phytodienoic acid containing acylated phosphatidylglycerol during the hypersensitive response in Arabidopsis. Phytochemistry 101:65-75. https://doi.org/10.1016/j.phytochem.2014.01. 020

Nilsson AK, Johansson ON, Fahlberg P et al (2015) Acylated monogalactosyl diacylglycerol: prevalence in the plant kingdom and identification of an enzyme catalyzing galactolipid head group acylation in Arabidopsis thaliana. Plant J 84:1152-1166. https://doi.org/10.1111/tpj.13072

Nilsson AK, Fahlberg P, Johansson ON et al (2016) The activity of HYDROPEROXIDE LYASE 1 regulates accumulation of galactolipids containing 12-oxo-phytodienoic acid in Arabidopsis. J Exp Bot 67:5133-5144. https://doi.org/10. 1093/jxb/erw278

Ohashi T, Ito Y, Okada M, Sakagami Y (2005) Isolation and stomatal opening activity of two oxylipins from Ipomoea tricolor. Bioorgan Med Chem Lett 15:263-265. https://doi. org/10.1016/j.bmcl.2004.10.088

Pedras MSC, To QH (2017) Defense and signalling metabolites of the crucifer Erucastrum canariense: synchronized abiotic induction of phytoalexins and galacto-oxylipins. Phytochemistry 139:18-24. https://doi.org/10.1016/j. phytochem.2017.03.005

Prost I, Dhondt S, Rothe G et al (2005) Evaluation of the antimicrobial activities of plant oxylipins supports their involvement in defense against pathogens. Plant Physiol 139:1902-1913. https://doi.org/10.1104/pp.105.066274

Savchenko T, Kolla VA, Wang C-Q et al (2014) Functional convergence of oxylipin and abscisic acid pathways controls stomatal closure in response to drought. Plant Physiol 164:1151-1160. https://doi.org/10.1104/pp.113.234310

Schafer M, Fischer C, Meldau S et al (2011) Lipase activity in insect oral secretions mediates defense responses in Arabidopsis. Plant Physiol 156:1520-1534. https://doi.org/10. 1104/pp.111.173567 
Shigemori H, Nakajyo H, Hisamatsu Y et al (2006) Arabidopside F, a new oxylipin from Arabidopsis thaliana. Heterocycles 69:295-302. https://doi.org/10.3987/COM-06$\mathrm{S}(\mathrm{O}) 33$

Shigemori H, Nakajyo H, Hisamatsu Y et al (2011) Structureactivity relationships on senescence-promoting effect of Arabidopsides from Arabidopsis thaliana. Heterocycles 83:57-62. https://doi.org/10.3987/COM-10-12092

Stelmach BA, Müller A, Hennig P et al (2001) A novel class of oxylipins, sn1-O-(12-Oxophytodienoyl)- sn2-O-(hexadecatrienoyl)-monogalactosyl diglyceride, from Arabidopsis thaliana. J Biol Chem 276:12832-12838. https://doi.org/ 10.1074/jbc.M010743200

Stintzi A, Weber H, Reymond P et al (2001) Plant defense in the absence of jasmonic acid: the role of cyclopentenones. Proc Natl Acad Sci 98:12837-12842. https://doi.org/10. 1073/pnas.211311098

Stumpe M, Feussner I (2006) Formation of oxylipins by CYP74 enzymes. Phytochem Rev 5:347-357. https://doi.org/10. 1007/s11101-006-9038-9

Stumpe M, Carsjens J-G, Gobel C, Feussner I (2008) Divinyl ether synthesis in garlic bulbs. J Exp Bot 59:907-915. https://doi.org/10.1093/jxb/ern010

Tjellström H, Andersson MX, Larsson KE, Sandelius AS (2008) Membrane phospholipids as a phosphate reserve: the dynamic nature of phospholipid-to-digalactosyl diacylglycerol exchange in higher plants. Plant Cell Environ 31:1388-1398. https://doi.org/10.1111/j.1365-3040.2008. 01851.X

Uchiyama A, Yaguchi T, Nakagawa H et al (2018) Biosynthesis and in vitro enzymatic synthesis of the isoleucine conjugate of 12-oxo-phytodienoic acid from the isoleucine conjugate of $\alpha$-linolenic acid. Bioorg Med Chem Lett 28:1020-1023. https://doi.org/10.1016/j.bmcl.2018.02.030

Vick BA, Zimmerman DC (1987) Pathways of fatty acid hydroperoxide metabolism in spinach leaf chloroplasts. Plant Physiol 85:1073-1078. https://doi.org/10.1104/pp. 85.4.1073

Vijayan P, Shockey J, Levesque CA et al (1998) A role for jasmonate in pathogen defense of Arabidopsis. Proc Natl Acad Sci 95:7209-7214. https://doi.org/10.1073/pnas.95. 12.7209

Vu HS, Tamura P, Galeva NA et al (2012) Direct infusion mass spectrometry of oxylipin-containing Arabidopsis membrane lipids reveals varied patterns in different stress responses. Plant Physiol 158:324-339. https://doi.org/10. 1104/pp.111.190280

Vu HS, Roth MR, Tamura P et al (2014) Head-group acylation of monogalactosyldiacylglycerol is a common stress response, and the acyl-galactose acyl composition varies with the plant species and applied stress. Physiol Plant 150:517-528. https://doi.org/10.1111/ppl.12132

Vu HS, Roston R, Shiva S et al (2015) Modifications of membrane lipids in response to wounding of Arabidopsis thaliana leaves. Plant Signal Behav. https://doi.org/10. 1080/15592324.2015.1056422

Wang K, Froehlich JE, Zienkiewicz A et al (2017) A plastid phosphatidylglycerol lipase contributes to the export of acyl groups from plastids for seed oil biosynthesis. Plant Cell 29:1678-1696. https://doi.org/10.1105/tpc.17.00397
Wang K, Guo Q, Froehlich JE et al (2018) Two abscisic acidresponsive plastid lipase genes involved in jasmonic acid biosynthesis in Arabidopsis thaliana. Plant Cell 30:1006-1022. https://doi.org/10.1105/tpc.18.00250

Wasternack C, Feussner I (2018) The oxylipin pathways: biochemistry and function. Annu Rev Plant Biol 69:363-386. https://doi.org/10.1146/annurev-arplant-042817-040440

Wasternack C, Hause B (2013) Jasmonates: biosynthesis, perception, signal transduction and action in plant stress response, growth and development. An update to the 2007 review in Annals of Botany. Ann Bot 111:1021-1058. https://doi.org/10.1093/aob/mct067

Wasternack C, Hause B (2018) A bypass in jasmonate biosynthesis-the OPR3-independent formation. Trends Plant Sci 23:276-279. https://doi.org/10.1016/j.tplants.2018.02.011

Wasternack C, Kombrink E (2010) Jasmonates: structural requirements for lipid-derived signals active in plant stress responses and development. ACS Chem Biol 5:63-77. https://doi.org/10.1021/cb900269u

Wasternack C, Song S (2016) Jasmonates: biosynthesis, metabolism, and signaling by proteins activating and repressing transciption. J Exp Bot 68:1303-1321. https://doi.org/10. 1093/jxb/erw443

Wasternack C, Strnad M (2016) Jasmonate signaling in plant stress responses and development-active and inactive compounds. New Biotechnol 33:604-613. https://doi.org/ 10.1016/j.nbt.2015.11.001

Wasternack C, Strnad M (2018) Jasmonates: news on occurrence, biosynthesis, metabolism and action of an ancient group of signaling compounds. Int J Mol Sci 19:2539. https://doi.org/10.3390/ijms19092539

Xiao S, Gao W, Chen Q-F et al (2010) Overexpression of Arabidopsis Acyl-CoA binding protein ACBP3 promotes starvation-induced and age-dependent leaf senescence. Plant Cell Online 22:1463-1482. https://doi.org/10.1105/ tpc. 110.075333

Yang W, Devaiah SP, Pan X et al (2007) AtPLAI Is an acyl hydrolase involved in basal jasmonic acid production and Arabidopsis Resistance to Botrytis cinerea. J Biol Chem 282:18116-18128. https://doi.org/10.1074/jbc. M700405200

Yang W-Y, Zheng Y, Bahn SC et al (2012) The patatin-containing phospholipase A pPLAII $\alpha$ modulates oxylipin formation and water loss in Arabidopsis thaliana. Mol Plant 5:452-460. https://doi.org/10.1093/mp/ssr118

Zábranská M, Vrkoslav V, Sobotníková J, Cvačka J (2012) Analysis of plant galactolipids by reversed-phase highperformance liquid chromatography/mass spectrometry with accurate mass measurement. Chem Phys Lipids 165:601-607. https://doi.org/10.1016/j.chemphyslip.2012. 03.002

Zhao H, Wang J, Xie C et al (2013) Study on fingerprints of different organs of Arabidopsis thaliana by using UPLC/ ESI-Q-TOF MS. Asian J Chem 25:3023-3029. https://doi. org/10.14233/ajchem.2013.13496

Zoeller M, Stingl N, Krischke M et al (2012) Lipid profiling of the Arabidopsis hypersensitive response reveals specific lipid peroxidation and fragmentation processes: biogenesis of pimelic and azelaic acid. Plant Physiol 160:365-378. https://doi.org/10.1104/pp.112.202846 